\title{
Characterization of the non-covalent docking motif in the isolated reactant complex of a double proton-coupled electron transfer reaction with cryogenic ion spectroscopy
}

Cite as: J. Chem. Phys. 152, 234309 (2020); https://doi.org/10.1063/5.0012176

Submitted: 28 April 2020 . Accepted: 27 May 2020 . Published Online: 18 June 2020

Evan H. Perez (D), Fabian S. Menges (D), Mauricio Cattaneo (D), James M. Mayer (D), and Mark A. Johnson (iD)

\section{Lock-in Amplifiers up to $600 \mathrm{MHz}$}
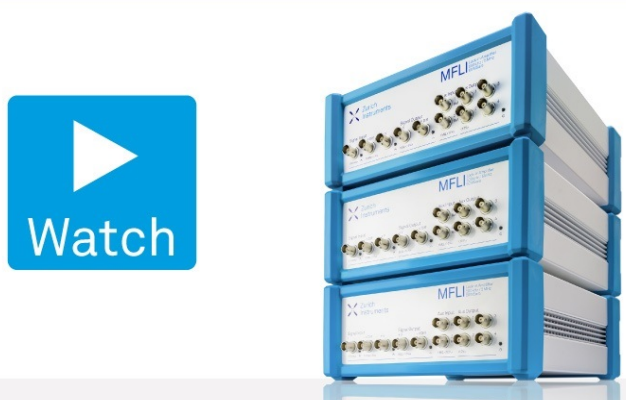


\title{
Characterization of the non-covalent docking motif in the isolated reactant complex of a double proton-coupled electron transfer reaction with cryogenic ion spectroscopy
}

Cite as: J. Chem. Phys. 152, 234309 (2020); doi: 10.1063/5.0012176

Submitted: 28 April 2020 - Accepted: 27 May 2020 •

Published Online: 18 June 2020

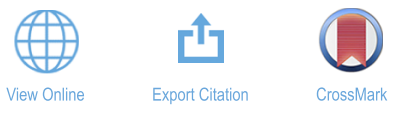

Evan H. Perez, ${ }^{1}$ (D) Fabian S. Menges, ${ }^{1}$ (D) Mauricio Cattaneo, ${ }^{2}$ (D) James M. Mayer, ${ }^{1}$ (D) and Mark A. Johnson ${ }^{1, a)}$ (iD)

AFFILIATIONS

'Department of Chemistry, Yale University, 225 Prospect St., New Haven, Connecticut 06520, USA

${ }^{2}$ INQUINOA-CONICET, Instituto de Química Física, Facultad de Bioquímica, Química y Farmacia, Universidad Nacional de Tucumán, T4000INI San Miguel de Tucumán, Argentina

a) Author to whom correspondence should be addressed: mark.johnson@yale.edu

\begin{abstract}
The solution kinetics of a proton-coupled electron transfer reaction involving two-electron oxidation of a Ru compound with concomitant transfer of two protons to a quinone derivative have been interpreted to indicate the formation of a long-lived intermediate between the reactants. We characterize the ionic reactants, products, and an entrance channel reaction complex in the gas phase using high-resolution mass spectrometry augmented by cryogenic ion IR photodissociation spectroscopy. Collisional activation of this trapped entrance channel complex does not drive the reaction to products but rather yields dissociation back to reactants. Electronic structure calculations indicate that there are four low-lying isomeric forms of the non-covalently bound complex. Comparison of their predicted vibrational spectra with the observed band pattern indicates that the $\mathrm{C}=\mathrm{O}$ groups of the ortho-quinone attach to protons on two different $-\mathrm{NH}_{2}$ groups of the reactant scaffold, exhibiting strong O-H-N contact motifs. Since collisional activation does not lead to the products observed in the liquid phase, these results indicate that the reaction most likely proceeds through reorientation of the $\mathrm{H}$-atom donor ligand about the metal
\end{abstract} center.

Published under license by AIP Publishing. https://doi.org/10.1063/5.0012176

\section{INTRODUCTION}

Recent advances in cold ion vibrational spectroscopy, coupled with ambient ionization methods, enable structural characterization of increasingly complex molecular ensembles. ${ }^{1}$ An important class of species becoming accessible with these methods involves trapping non-covalently bound complexes between reactants, ${ }^{2-5}$ thus providing an unprecedented view of how the two species dock together and how this arrangement is related to the reaction coordinate that leads to products. This strategy was employed earlier to determine the docking arrangements at play in a biomimetic bromination catalyst, ${ }^{2}$ as well as the degree of small molecule $\left(\mathrm{CO}_{2}, \mathrm{~N}_{2}\right.$, and $\left.\mathrm{O}_{2}\right)$ activation by the active coordination site on an organometallic coordination compound. ${ }^{6,7}$ Here, we expand the scope of this approach to address the geometry of a non-covalently bound complex formed by the reactants in a proton-coupled electron transfer reaction between a $\mathrm{Ru}^{\mathrm{II}}$ coordination compound and the orthoquinone (hereafter denoted reaction I) depicted in Fig. 1. From the experimental standpoint, this system presents a more demanding scenario than those studied previously ${ }^{6,8-10}$ because of the +2 charge state of the catalyst under study and the many isotopologues arising from the $\mathrm{Ru}$ and $\mathrm{C}$ atoms. This challenge has very recently been met, however, by coupling cold ion spectroscopy with a commercial high-resolution mass spectrometer (Thermo Velos Pro), which we herein exploit for this experimental demonstration. ${ }^{11,1}$

We chose this PCET system because it involves the interesting scenario where two hydrogen atoms are transferred to the orthoquinone along with two-electron oxidation of $\mathrm{Ru}^{\mathrm{II}}$ to $\mathrm{Ru}^{\mathrm{IV}} \cdot{ }^{13}$ 
a)

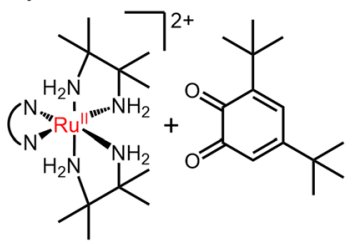

Ru" $(\mathrm{en} *)_{2}$ TBOQ b)

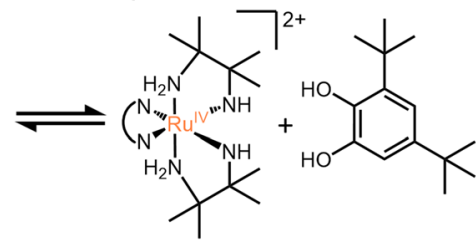

$\mathrm{Ru}^{\mathrm{IV}}(\mathrm{en} * \mathrm{H})_{2}$ TBOHQ

FIG. 1. The two-electron, two-proton PCET reaction featuring the oxidation of the ruthenium metal center from (a) $+\|\left(\left[\mathrm{Ru}^{\mathrm{II}}\left(\mathrm{en}^{*}\right)_{2}\right]^{2+}=\right.$ $\left[\mathrm{Ru}^{\prime \prime} \text { (bpy) }\left(\mathrm{H}_{2} \mathrm{NCMe}_{2} \mathrm{CMe}_{2} \mathrm{NH}_{2}\right)_{2}\right]^{2+}$ ) to (b) +IV $\left(\left[\mathrm{Ru}^{\mathrm{IV}}\left(\mathrm{en}^{*}-\mathrm{H}\right)_{2}\right]^{2+}=\right.$ $\left.\left[\mathrm{Ru}^{\mathrm{IV}}(\mathrm{bpy})\left(\mathrm{H}_{2} \mathrm{NCMe}_{2} \mathrm{CMe}_{2} \mathrm{NH}\right)_{2}\right]^{2+}\right)$. The reactant ortho-quinone (TBOQ = 3,5-di-tert-butyl ortho-quinone) is converted to product ortho-hydroquinone (TBOHQ = 3,5-di-tert-butyl ortho-hydroquinone)

As such, this "double-PCET" process raises the question of whether the entrance channel complex can be captured in a configuration involving $\mathrm{C}=\mathrm{O}$ interactions with the two reactive protons on the quinone. The motivation for addressing this question in part derives from an earlier investigation ${ }^{13}$ of the mechanism for this reaction using traditional tools of chemical analysis. UV-Vis spectroscopy of the reaction mixture, for example, revealed an isosbestic point, indicating production of $\mathrm{Ru}^{\mathrm{IV}}$ without buildup of an intermediate $\mathrm{Ru}^{\text {III }}$ species. ${ }^{13}$ In addition, features in the ${ }^{1} \mathrm{H}$-NMR spectra were interpreted in the context of the formation of a long-lived association complex between the reactants. In this report, we examine the intrinsic hydrogen-bonding interaction of the isolated $\mathrm{Ru}^{\mathrm{II}}$ amine dication $\left(\left[\mathrm{Ru}^{\mathrm{II}}(\mathrm{bpy})\left(\mathrm{H}_{2} \mathrm{NCMe}_{2} \mathrm{CMe}_{2} \mathrm{NH}_{2}\right)_{2}\right]^{2+}\left(\right.\right.$ bpy $=2,2^{\prime}-$ bipyridine, $\mathrm{H}_{2} \mathrm{NCMe}_{2} \mathrm{CMe}_{2} \mathrm{NH}_{2}=2,3$-dimethyl-2,3-butanediamine $\left.=\mathrm{en}^{*}\right)$, denoted $\left[\mathrm{Ru}^{\mathrm{II}}\left(\mathrm{en}^{*}\right)_{2}\right]^{2+}$ with the quinone (3,5-di-tert-butyl ortho-quinone, denoted TBOQ), where both are displayed schematically in Fig. 1(a) This characterization was accomplished by extracting the ions from solution using an electrospray ambient ion source and cryogenically cooling them to $\sim 20 \mathrm{~K}$ in a radio frequency ion trap. Their vibrational spectra were then obtained in a linear action mode by IR photodissociation of a weakly bound $\mathrm{D}_{2}$ molecule. ${ }^{1,14-17}$ Finally, the nature of the binding pocket was assessed by comparing the observed band patterns with those calculated for various local minima and consideration of their relative computed energies. ${ }^{18-20}$

\section{EXPERIMENTAL}

$\left[\mathrm{Ru}^{\mathrm{II}}\left(\mathrm{en}^{*}\right)_{2}\left(\mathrm{PF}_{6}\right)_{2}\right]$ and $\left[\mathrm{Ru}^{\mathrm{IV}}\left(\mathrm{en}^{*}-\mathrm{H}\right)_{2}\left(\mathrm{PF}_{6}\right)_{2}\right]$ were synthesized according to protocols reported previously. ${ }^{13}$ 3,5-di-tertbutyl ortho-quinone (TBOQ), 3,5-di-tert-butyl ortho-hydroquinone (TBOHQ), and acetonitrile (HPLC grade) were purchased from Sigma-Aldrich and used without further purification. The $\left[\mathrm{Ru}^{\mathrm{II}}\left(\mathrm{en}^{*}\right)\right.$ TBOQ $]^{2+}$ complex ion was generated via electrospray ionization using a $(\sim 1 \mathrm{mM}), 1: 1$ solution of $\left[\mathrm{Ru}^{\mathrm{II}}\left(\mathrm{en}^{*}\right)_{2}\left(\mathrm{PF}_{6}\right)_{2}\right]$ and TBOQ in acetonitrile. Mass spectra and photofragmentation infrared spectra were collected using a hybrid instrument that combines a commercial Thermo Fisher Scientific LTQ Orbitrap Velos Pro with a custom-built triple-focusing time-of-flight photofragmentation mass spectrometer, shown in Fig. S1 and described in detail

previously. ${ }^{11}$ In brief, mass spectra were collected using the instrument's Orbitrap capability at maximum resolution $(\Delta \mathrm{m} / \mathrm{m}$ $=100000$ ) before transmitting the ions to the photofragmentation spectrometer for infrared structural characterization. The vibrational spectra were obtained by photodissociating weakly bound $\mathrm{D}_{2}$ molecules using the "messenger tagging" approach, ${ }^{21}$ where the $\mathrm{D}_{2}$ molecules were condensed onto target ions in a radio frequency ion trap held at $\sim 20 \mathrm{~K}$.

Density functional theory (DFT) was used to calculate the normal modes of the target ions at the M062X/6-311G* level of theory $(\mathrm{C}, \mathrm{H}, \mathrm{N}, \mathrm{O}, \mathrm{P}, \mathrm{F})$ and def2-TZVP with an effective core potential for the Ru center. ${ }^{22,23}$ All calculations were conducted using the Gaussian $09^{24}$ suite of electronic structure software. Crystal structures of $\left[\mathrm{Ru}^{\mathrm{II}}\left(\mathrm{en}^{*}\right)_{2}\left(\mathrm{PF}_{6}\right)_{2}\right]$ and $\left[\mathrm{Ru}^{\mathrm{IV}}\left(\mathrm{en}^{*}-\mathrm{H}\right)_{2}\left(\mathrm{PF}_{6}\right)_{2}\right]$ were used as initial structures for DFT optimization after omitting the $\mathrm{PF}_{6}{ }^{-}$ anion. ${ }^{25}$ A conformational survey was performed in which TBOQ was placed at different positions around the $\mathrm{NH}$ moieties in the $\left[\mathrm{Ru}^{\mathrm{II}}\left(\mathrm{en}^{*}\right)_{2}\right]^{2+}$ compound groups and then optimizing the initial structure into the local energetic minima. See Table S1 of the supplementary material for relative energies and BSSE corrected binding energies. Additionally, all possible isomers for $\left[\mathrm{Ru}^{\mathrm{IV}}\left(\mathrm{en}^{*}-\mathrm{H}\right)_{2}\right]$ after double proton abstraction from the $e n^{*}$ groups were identified. The relative energies of the isolated reactants and products, as well as their intermediates, are displayed in Fig. S2.

\section{RESULTS AND DISCUSSION}

\section{A. Mass analysis of complex formation with ESI}

The kinetics and energetics of $\left[\mathrm{Ru}^{\mathrm{II}}\left(\mathrm{en}^{*}\right)_{2}\right]^{2+}$ reactions with various quinones have been characterized extensively by Cattaneo et al. ${ }^{13}$ Of these, we selected the endothermic reaction with TBOQ $\left(\Delta \mathrm{G}^{0}=1.5 \mathrm{kcal} / \mathrm{mol}\right.$ in acetone $)$ on the basis that both reactants should be present at significant concentrations in equilibrium solutions of acetonitrile prepared with equimolar $(\sim 1 \mathrm{mM})$ initial concentrations of both reactants. Figure 2(a) presents the electrospray ionization (ESI) mass spectrum of the $\left[\mathrm{Ru}^{\mathrm{II}}\left(\mathrm{en}^{*}\right)_{2}\right]^{2+}$ dication extracted from a $1 \mathrm{mM}$ solution of the $\left[\mathrm{Ru}^{\mathrm{II}}\left(\mathrm{en}^{*}\right)_{2}\left(\mathrm{PF}_{6}\right)_{2}\right]$ salt. The stoichiometry of this species was verified using the high-resolution capability of the mass analyzer, with the resulting mass spectrum displayed in Fig. S3. Introduction of the TBOQ neutral reactant into the solution yields the mass spectrum shown in Fig. 2(b), confirming formation of a binary complex between $\left[\mathrm{Ru}^{\mathrm{II}}\left(\mathrm{en}^{*}\right)_{2}\right]^{2+}$ and TBOQ with $\mathrm{m} / \mathrm{z}$ of 355.19 . Furthermore, we mixed solutions of each ruthenium complex $\left(\left[\mathrm{Ru}^{\mathrm{II}}\left(\mathrm{en}^{*}\right)_{2}\right]^{2+}\right.$ and $\left.\left[\mathrm{Ru}^{\mathrm{IV}}\left(\mathrm{en}^{*}-\mathrm{H}\right)_{2}\right]^{2+}\right)$ with solutions of TBOQ or TBOHQ. In general, we might expect to capture all four binary combinations of reactants and products, but of these, we only observed TBOQ complexes with $\left[\mathrm{Ru}^{\mathrm{II}}\left(\mathrm{en}^{*}\right)_{2}\right]^{2+}$ and $\left[\mathrm{Ru}^{\mathrm{IV}}\left(\mathrm{en}^{*}-\mathrm{H}\right)_{2}\right]^{2+}$; attachment of TBOHQ was never observed. This is consistent with the calculated binding energies plotted in Fig. S2, which predict that the binding energies of the various isomeric forms of the exit channel complexes are about half those of the entrance channel. Although these ions $\left(\left[\mathrm{Ru}^{\mathrm{II}}\left(\mathrm{en}^{*}\right)_{2}\right]^{2+}\right.$ and $\left.\left[\mathrm{Ru}^{\mathrm{IV}}\left(\mathrm{en}^{*}-\mathrm{H}\right)_{2}\right]^{2+}\right)$ display interleaving isotopic distributions, the high-resolution mode of the Orbitrap enables clear differentiation to establish the presence of both species, as shown in Fig. S3. $\left[\mathrm{Ru}^{\mathrm{IV}}\left(\mathrm{en}^{*}-\mathrm{H}\right)_{2} \mathrm{TBOQ}^{2+}\right.$ and $\left[\mathrm{Ru}^{\mathrm{IV}}\left(\mathrm{en}^{*}-\mathrm{H}\right)_{2}\right]^{2+}$ were observed to build up over time as the reactant $\left[\mathrm{Ru}^{\mathrm{II}}\left(\mathrm{en}^{*}\right)_{2}\right]^{2+}$ degrades and 
(a)

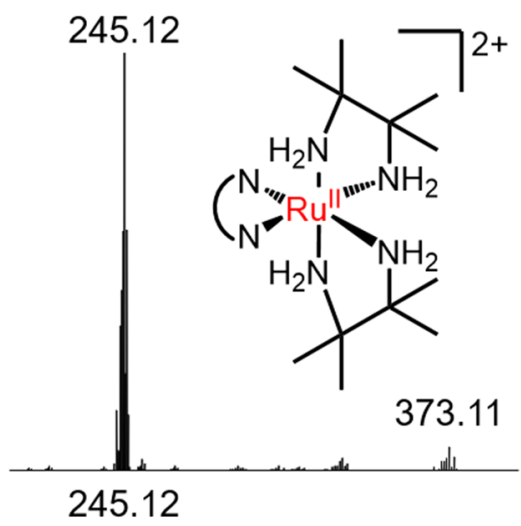

(b)

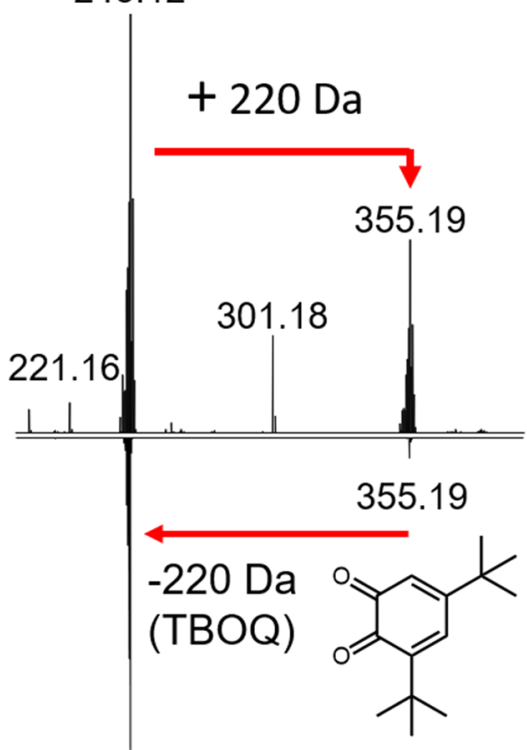

245.12
$355.19 \mathrm{~m} / \mathrm{z}$ species is indeed the non-covalently bound, entrance channel complex of reaction I. We speculate that the absence of the non-covalent adducts with the TBOHQ product is due to the fact that they are too fragile to survive the ion transfer optics in the commercial ion source. On the other hand, an extended survey of CID conditions of the mass isolated $\left[\mathrm{Ru}^{\mathrm{II}}\left(\mathrm{en}^{*}\right)_{2} \mathrm{TBOQ}\right]^{2+}$ did not yield formation of $\left[\mathrm{Ru}^{\mathrm{IV}}\left(\mathrm{en}^{*}-\mathrm{H}\right)_{2}\right]^{2+}$ products by collisional activation, raising the question of whether this non-covalently bound complex is indeed arranged along the entrance channel reaction coordinate. In contrast, we note that for the bare $\left[\mathrm{Ru}^{\mathrm{II}}\left(\mathrm{en}^{*}\right)_{2}\right]^{2+}$ reactant ion, CID yields elimination of singly charged fragments in addition to simple ejection of the neutral ligand $\mathrm{en}^{*}$ (Table S2 and Figs. S3 and S4). The production of two singly charged fragments necessarily involves proton migration in which one of the two en* ligands abstracts a proton, presumably from the other en ${ }^{*}$ ligand, to produce $\left[\mathrm{en}^{*}+\mathrm{H}\right]^{+}$and $\left[\mathrm{Ru}^{\mathrm{II}}\left(\mathrm{en}^{*}\right)\left(\mathrm{en}^{*}-\mathrm{H}\right)\right]^{+}$.

\section{B. Cryogenic vibrational spectroscopy}

\section{1. $\left[R u^{\prime \prime}\left(e n^{*}\right)_{2}\right]^{2+}$ and $\left[R u^{I V}\left(e n^{*}-H\right)_{2}\right]^{2+}$}

The observed vibrational spectrum of the $\left[\mathrm{Ru}^{\mathrm{II}}\left(\mathrm{en}^{*}\right)_{2}\right]^{2+} \bullet \mathrm{D}_{2}$ ion in the NH stretching region (black trace) is presented in Fig. 3(a), along with the calculated harmonic spectrum [inverted bars in Fig. 3(b)] for the structure presented in Fig. S5. As indicated in the schematic structure at the upper right of Fig. 3, there are four $\mathrm{NH}_{2}$ groups coordinated to the metal center in the $C_{2}$-symmetry

(a)

(b)
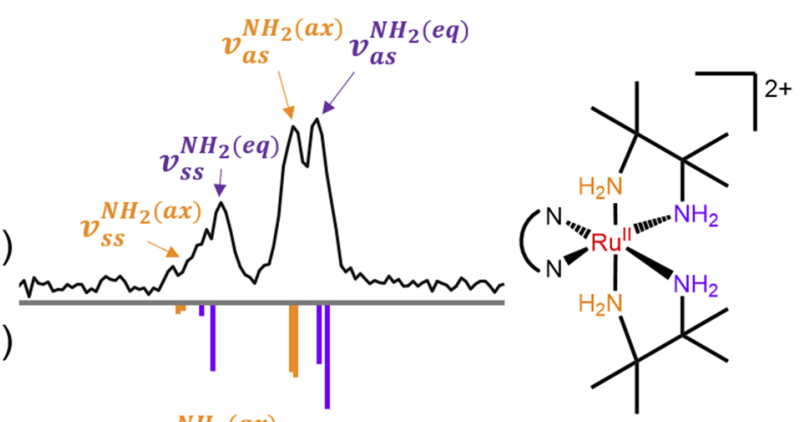

FIG. 2. (a) Mass spectrum of the solution containing the $\mathrm{Ru}^{\prime \prime}\left(\mathrm{en}^{*}\right)_{2}\left(\mathrm{PF}_{6}\right)_{2}$ salt displaying the $\left[\mathrm{Ru}^{\prime \prime}\left(\mathrm{en}^{*}\right)_{2}\right]^{2+}$ ion at $245 \mathrm{~m} / \mathrm{z}$. (b) Addition of TBOQ to the $\mathrm{Ru}^{\prime \prime}\left(\mathrm{en}^{*}\right)_{2}\left(\mathrm{PF}_{6}\right)_{2}$ solution leads to the appearance of a mass at $355 \mathrm{~m} / \mathrm{z}$, which is assigned to the $\left[\mathrm{Ru}^{\prime \prime}\left(\mathrm{en}^{*}\right)_{2} \mathrm{TBOQ}\right]^{2+}$ ion. (c) Collision Induced Dissociation (CID) of the $\left[\mathrm{Ru}^{\prime \prime}\left(\mathrm{en}^{*}\right)_{2} \mathrm{TBOQ}\right]^{2+}$ ion displaying loss of TBOQ without hydrogen transfer. See the supplementary material for conformation of stoichiometry by high resolution.

were isolated and characterized without interference by spraying a solution containing only $\left[\mathrm{Ru}^{\mathrm{IV}}\left(\mathrm{en}^{*}-\mathrm{H}\right)_{2}\right]^{2+}$ and TBOQ.

To evaluate the chemical nature of the $\left[\mathrm{Ru}^{\mathrm{II}}\left(\mathrm{en}^{*}\right)_{2}\right]^{2+}$ and $\left[\mathrm{Ru}^{\mathrm{IV}}\left(\mathrm{en}^{*}-\mathrm{H}\right)_{2}\right]^{2+}$ dications with masses that nominally correspond to the addition of TBOQ, we carried out collisional induced dissociation (CID) in the linear quadrupole ion trap (LTQ) section of the Velos Pro. In both cases, we exclusively observed the ejection of neutral TBOQ, with the CID mass spectrum of the $\left[\mathrm{Ru}^{\mathrm{II}}\left(\mathrm{en}^{*}\right)_{2} \mathrm{TBOQ}\right]^{2+}$ complex displayed in Fig. 2(c). As such, we conclude that the

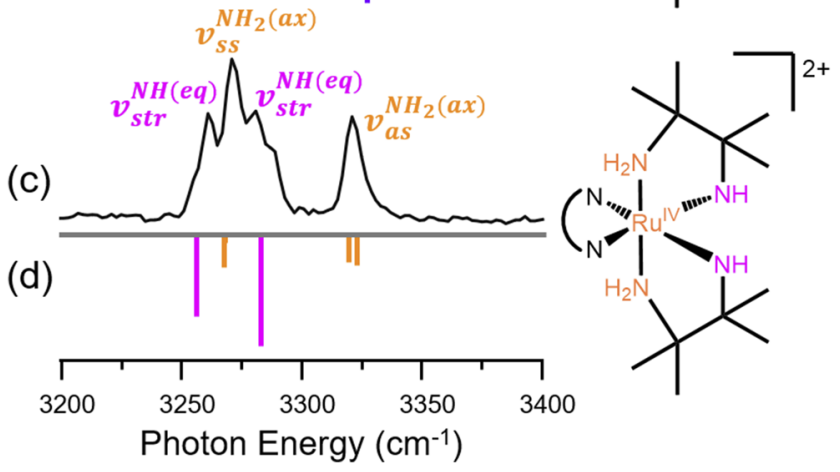

FIG. 3. $\mathrm{NH}_{2}$ stretching region of the photofragmentation $\mathrm{IR}$ spectrum of $\left[\mathrm{Ru}^{\mathrm{II}}\left(\mathrm{en}^{*}\right)_{2}\right]^{2+} \bullet \mathrm{D}_{2}(\mathrm{a})$ and $\left[\mathrm{Ru}^{\mathrm{IV}}\left(\mathrm{en}^{*}-\mathrm{H}\right)_{2}\right]^{2+} \bullet \mathrm{D}_{2}$ (c). DFT calculated frequencies [(b) and (d)] were scaled by 0.9425:1 to match the broadened line shape to the experiment maxima. Equatorial $\mathrm{NH}_{2}$ groups (and $\mathrm{NH}$ groups) are highlighted in purple and pink, respectively, while axial $\mathrm{NH}_{2}$ groups are labeled in orange. 
$\left[\mathrm{Ru}^{\mathrm{II}}\left(\mathrm{en}^{*}\right)_{2}\right]^{2+}$ compound, resulting in eight vibrational fundamentals. These are divided into four symmetric $\left(v_{s s}\right)$ and four asymmetric $\left(v_{a s}\right)$ normal modes derived from the $\mathrm{NH}$ stretches. The local environments of these $\mathrm{NH}_{2}$ moieties differ according to their positions relative to the aromatic bipyridine ligand. Specifically, the two equatorial $\mathrm{NH}_{2}$ groups [same plane as the bipyridine ligand, purple in the upper structure inset of Fig. 3, $\mathrm{NH}_{2}(\mathrm{eq})$ ] are arranged to promote electronic interaction with the bipyridine ligand, a process that is suppressed in the axial $\mathrm{NH}_{2}$ groups [orange in the upper inset of Fig. 3, $\mathrm{NH}_{2}(\mathrm{ax})$ ]. The $v_{a s}$ band arising from the $\mathrm{NH}_{2}(\mathrm{eq})$ groups lies just above those assigned to $v_{a s}$ from the $\mathrm{NH}_{2}(\mathrm{ax})$ groups, which accounts for the doublet structure of the observed $v_{a s}$ band centered at $\sim 3325 \mathrm{~cm}^{-1}$. The calculated patterns [inverted trace in Fig. 3(b)] underlying this doublet are further split according to the collective in- and out-of-phase nature of the weakly coupled groups in each class, but this fine structure is not observed at the present experimental resolution $\left(\sim 5 \mathrm{~cm}^{-1}\right)$. The observed asymmetric peak near $3275 \mathrm{~cm}^{-1}$ in Fig. $3(\mathrm{a})$ can then be assigned to the expected $v_{s s} \mathrm{NH}_{2}(e q)$ and $v_{s s}^{\mathrm{NH}_{2}(a x)}$ bands, which are calculated to be evenly distributed in this region [orange and purple in Fig. 3(b)]. We note that the splitting between the $v_{s s}$ and $v_{a s}$ bands $\left(40 \mathrm{~cm}^{-1}\right)$ in the $\left[\mathrm{Ru}^{\mathrm{II}}\left(\mathrm{en}^{*}\right)_{2}\right]$ complex is smaller than that observed in methylamine $\left(66 \mathrm{~cm}^{-1}\right)$ and ethylenediamine $\left(61 \mathrm{~cm}^{-1}\right)$, although it is found to be reduced in complexes involving dicationic metal ions: zinc, cadmium, and mercury $\left(53 \mathrm{~cm}^{-1}, 55 \mathrm{~cm}^{-1}\right.$, and $55 \mathrm{~cm}^{-1}$, respectively). ${ }^{2}$

Figure 3(c) presents the vibrational spectrum of the $\left[\mathrm{Ru}^{\mathrm{IV}}\left(\mathrm{en}^{*}\right.\right.$ $\left.-\mathrm{H})_{2}\right]^{2+} \bullet \mathrm{D}_{2}$ product ion from reaction $\mathrm{I}$, which explores how the conversion of two of the $\mathrm{NH}_{2}(\mathrm{eq})$ groups to NHs impacts the spectrum. Consistent with the calculated pattern [Fig. 3(d)], this modification inverts the relative intensities of the feature in the $v_{a s}$ region and the absorption just below it. The strong band at $3275 \mathrm{~cm}^{-1}$ is predicted to drive from the $v_{s t r}^{\mathrm{NH}(e q)}$ fundamentals associated with the $\mathrm{NH}(\mathrm{eq})$ groups in the product ion [pink bars in Fig. 3(d)]. We note that all combinations (eq and ax) of the two amido $\mathrm{NH}$ locations were calculated (Fig. S6), and the lowest energy structure was that with the amido groups both occupying the equatorial (eq-eq) positions with respect to the bipyridine, as shown in Fig. S6(b), in agreement with the reported crystallographic structure. ${ }^{25}$ The (eq-ax and ax-ax) conformers are predicted to lie significantly higher in energy (by $15.0 \mathrm{kcal} / \mathrm{mol}$ and $25.4 \mathrm{kcal} / \mathrm{mol}$, respectively) and display vibrational band patterns that are significantly different than what is observed experimentally [see Figs. S6(c) and S6(d)]. We can rationalize the preference for the (eq-eq) isomer by the formation of a $\pi$ bond between the symmetric combination of filled amide $\mathrm{p}$ orbitals and the $\mathrm{Ru} \mathrm{d}_{\mathrm{xy}}$ orbital (considering the bpy ligand to lie in the xy plane). This interaction, which involves only one of the $\sigma$ nonbonding $t_{2 \mathrm{~g}}$-like d orbitals, accounts for the diamagnetism of the $\mathrm{d}^{4}\left[\mathrm{Ru}^{\mathrm{IV}}\left(\mathrm{en}^{*}-\mathrm{H}\right)_{2}\right]^{2+}$ compound. ${ }^{2}$

\section{The $\left[R u^{\prime \prime}\left(e n^{*}\right)_{2} T B O Q\right]^{2+}$ entrance channel complex}

Figure 4 compares the observed $\mathrm{D}_{2}$-tagged spectrum of the isolated $\left[\mathrm{Ru}^{\mathrm{II}}\left(\mathrm{en}^{*}\right)_{2}\right]^{2+}$ dication with that of the putative entrance channel complex, $\left[\mathrm{Ru}^{\mathrm{II}}\left(\mathrm{en}^{*}\right)_{2} \mathrm{TBOQ}\right]^{2+}$, in the high frequency $\mathrm{NH}$ stretching region as well as in the lower frequency range of the $\mathrm{NH}$ bending and $\mathrm{C}=\mathrm{O}$ stretching fundamentals. Although the highest energy $\mathrm{NH}$ feature of the $\left[\mathrm{Ru}^{\mathrm{II}}\left(\mathrm{en}^{*}\right)_{2}\right]^{2+}$ band near

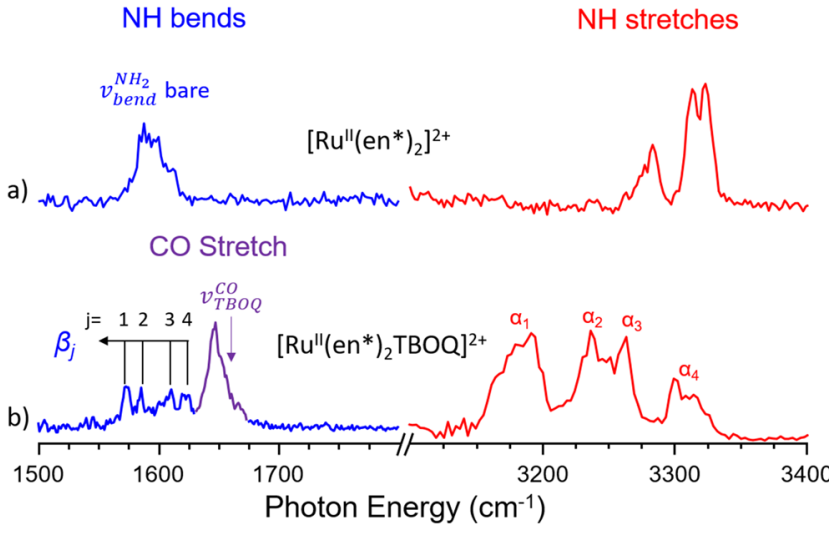

FIG. 4. Vibrational predissociation spectra of (a) $\left[\mathrm{Ru}^{\prime \prime}\left(\mathrm{en}^{*}\right)_{2}\right]^{2+} \bullet \mathrm{D}_{2}$ and (b) $\left[\mathrm{Ru}^{\prime \prime}\left(\mathrm{en}^{*}\right)_{2} \mathrm{TBOQ}\right]^{2+} \cdot \mathrm{D}_{2}$. The purple arrow in b) indicates the solution phase FTIR value for the $\mathrm{C}=\mathrm{O}$ stretching mode in neutral TBOQ.

$3325 \mathrm{~cm}^{-1}\left(\alpha_{4}\right)$ persists with some distortion in the line shape upon complexation, the dominant activity in the $\mathrm{NH}$ stretching region is dramatically red-shifted. Since two of the $-\mathrm{NH}_{2}$ groups are not involved in the interaction in all calculated structures, the highest energy feature $\left(\alpha_{4}\right)$ arises from the associated $\mathrm{NH}_{2}$ asymmetric stretch. The red-shifted features $\left(\alpha_{1-3}\right)$, on the other hand, are expected for the TBOQ adduct and are therefore traced to the stretching bands of the $\mathrm{NH}$ groups involved in hydrogen bonds to the quinone. In the lower energy fingerprint region, a very strong band (purple) near $1650 \mathrm{~cm}^{-1}$ appears upon complexation with the quinone, which lies just below the collective symmetric stretch of the two $\mathrm{C}=\mathrm{O}$ groups of the isolated quinone in solution $\left(1660 \mathrm{~cm}^{-1}\right),{ }^{27}$ indicated by the downward arrow denoted $v_{T B O Q}^{\mathrm{CO}}$ in Fig. 4(b). This feature establishes that the $\mathrm{C}=\mathrm{O}$ groups are intact in the complex because formation of $\mathrm{C}-\mathrm{OH}$ single bonds in the neutral TBOHQ product after PCET would yield much lower frequency fundamentals. ${ }^{28}$ We also note that the $\mathrm{NH}$ bending modes $\left(v_{b e n d}^{\mathrm{NH}_{2}}\right)$, which appear as an unresolved broad feature in the bare $\left[\mathrm{Ru}^{\mathrm{II}}\left(\mathrm{en}^{*}\right)_{2}\right]^{2+}$ spectrum, are split apart upon formation of the complex to form a set of distinct features $\left[\beta_{1-4}\right.$ in Fig. 4 (b) $]$. The fact that two of these $\left(\beta_{3,4}\right)$ lie above the bends in the bare reactant ion is consistent with the formation of NH-O linkages, which are known to blue shift the bending fundamentals. ${ }^{29}$ We remark that we have focused on the $\mathrm{NH}$ bending and $\mathrm{C}=\mathrm{O}$ stretching bands in this region because the $\mathrm{C}-\mathrm{C}$ stretching fundamentals, which also occur in this frequency range, are calculated to be much weaker as we describe further below.

We identified many local minima for the entrance channel complex that all feature two $\mathrm{H}$-bond docking sites in which the TBOQ $\mathrm{C}=\mathrm{O}$ groups attach to one of the two $\mathrm{NH}$ bonds in separate $-\mathrm{NH}_{2}$ groups. Interestingly, there are configurations in which the quinone binds to either both equatorial $\mathrm{NH}$ groups (eq-eq), which would nominally correspond to the two $\mathrm{H}$ atoms that are transferred in the $2 \times P C E T$ process, or structures where one $\mathrm{C}=\mathrm{O}$ binds to an equatorial $\mathrm{NH}$ and the other one to an axial group (eq-ax). Because the quinone is itself asymmetrical with respect to the locations of the 

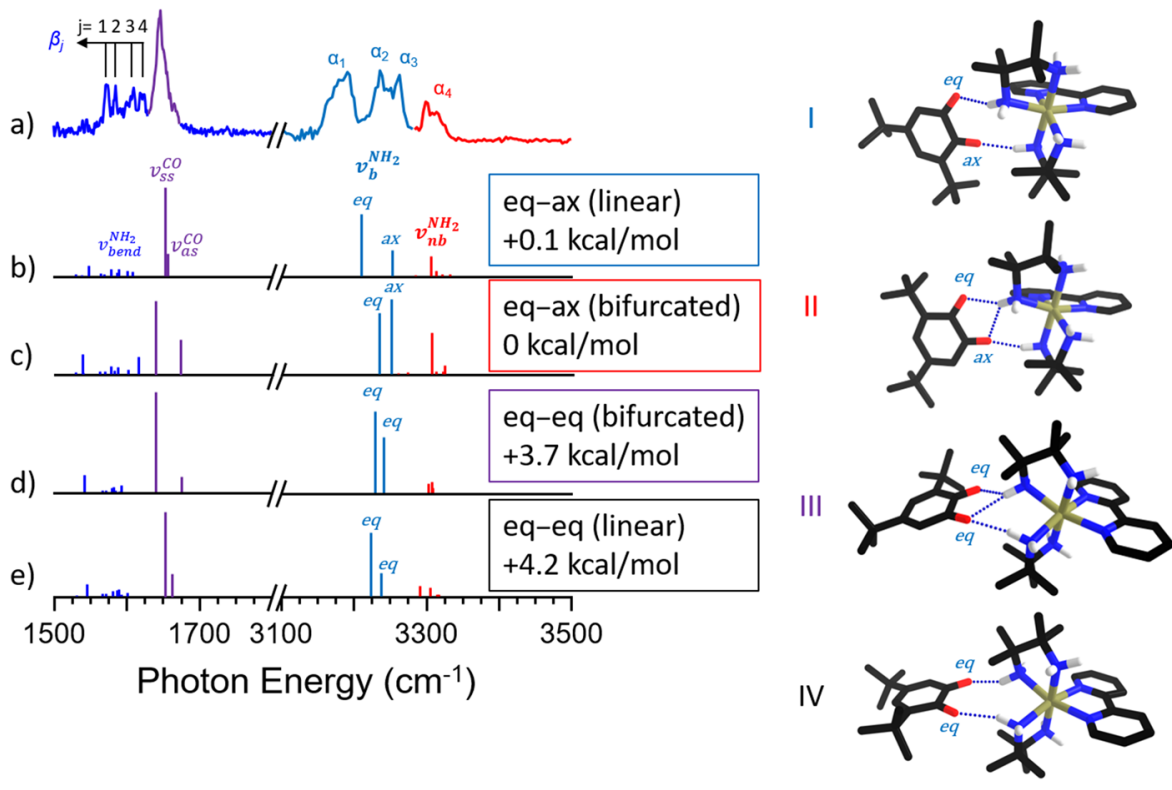

FIG. 5. Vibrational predissociation spectrum of (a) $\left[\mathrm{Ru}^{\prime \prime}\left(\mathrm{en}^{*}\right)_{2} \mathrm{TBOQ}\right]^{2+} \cdot \mathrm{D}_{2}$ with those calculated in (b) through (e) for the four isomers lying lowest in energy (relative values in boxes, after correction for vibrational ZPE). Calculated spectra are scaled by 0.9425 in order to match the $\mathrm{CO}$ and $\mathrm{a}_{4}$ bands of the experimental spectrum. Isomers III and IV [spectra (d) and (e), respectively] correspond to a hydrogen-bonding interaction with the two equatorial $\mathrm{NH}_{2}$ groups (eq-eq), whereas isomers I and II [spectra (b) and (c), respectively] feature attachment to one equatorial and one axial $\mathrm{NH}_{2}$ (eqax). Linear and bifurcated monikers indicate the nature of the hydrogen bonds between the two $\mathrm{C}=0$ groups and the two N-H groups. 3-D structures can be seen in supplementary material, Fig. S7.

two t-butyl groups, each of these forms occurs in two isomeric forms that differ by roughly $180^{\circ}$ rotation of the TBOQ in the docking site. This results in four low-lying isomers (hereafter denoted I, II, III, and IV) with the structures indicated at the right of Fig. 5. Rotatable pdf structures are included in Fig. S7 to better display the local interactions. Note that isomers II and III feature a bifurcated binding motif in which an $\mathrm{NH}$ group lies between two $\mathrm{C}=\mathrm{O}$ groups, while I and IV are based on more local quasilinear $(\mathrm{C}=\mathrm{O}-\mathrm{HN})$ hydrogen bond linkages. The two eq-ax isomers (I and II) are calculated to be nearly degenerate and lie about $4 \mathrm{kcal} / \mathrm{mol}$ lower in energy than those (III and IV) with the eq-eq binding motif.

Figure 5 compares the (scaled) predicted harmonic spectra [(b)-(e)] of the four lowest lying isomers with the observed spectrum of $\left[\mathrm{Ru}^{\mathrm{II}}\left(\mathrm{en}^{*}\right)_{2} \mathrm{TBOQ}\right]^{2+} \bullet \mathrm{D}_{2}$ in Fig. 5(a). Band positions and assignments are included in Table S3. It is of interest to note that, in all cases, the $\mathrm{NH}$ stretching fundamental associated with the eq $\mathrm{NH}$ group $\left(v_{b}^{\mathrm{NH}_{2}} e q\right)$ is calculated to be lowest in energy, which is expected to be the proton transferred in the PCET reaction. Of these, the spectrum calculated for isomer $\mathbf{I}$ is in overall best agreement with the observed bands in the $\mathrm{NH}$ and $\mathrm{C}=\mathrm{O}$ stretching regions. The situation regarding the splitting between the collective symmetric and asymmetric $\mathrm{C}=\mathrm{O}$ stretches is particularly useful for structure identification. Specifically, the two isomers (II and III) that feature bifurcated binding motifs to the $\mathrm{NH}$ groups are calculated to yield a clear splitting $\left(37 \mathrm{~cm}^{-1}\right.$ and $39 \mathrm{~cm}^{-1}$, respectively), while I and IV with more linear binding arrangements are more in line with the single, asymmetric $\mathrm{C}=\mathrm{O}$ stretching band in the observed spectrum. Based on the fact that the calculated pattern for isomer I in the $\mathrm{NH}$ stretching region is closest to the observed red-shifted bands, we propose that isomer I is the most likely candidate for the docking geometry of the entrance channel complex. We note, however, that although it is calculated to lie much higher in energy, we cannot rule out a contribution from isomer IV based on the spectrum alone since both isomers yield similar patterns for the $\mathrm{C}=\mathrm{O}$ stretches. Unfortunately, detailed comparisons in the $\mathrm{NH}$ stretching region are not straightforward as it is well known ${ }^{30}$ that multiplet structures are often observed in this region due to strong Fermi-resonance interactions between the red-shifted $\mathrm{NH}$ fundamentals and the $\mathrm{v}=2$ level of the $\mathrm{NH}$ bends. ${ }^{29-31}$ We illustrate this in Fig. S8, which establishes that incorporation of the Fermi resonance interactions between the predicted $\mathrm{NH}$ stretch and bending levels with a typical matrix element $\left(37 \mathrm{~cm}^{-1}\right)$ recovers the multiplet character of the observed spectrum. Having identified the most likely docking arrangement in the captured reactant complex, we note that only one of the two equatorial $\mathrm{NH}_{2}$ groups that are transformed into the product (which has two equatorial $\mathrm{NHs}$ ) is in direct contact with the carbonyl. As such, although it is an appealing scenario that the system docks in a natural position to execute a double protonelectron transfer with minimal participation of the surrounding network, this study indicates that the reaction pathway might well be more complex, involving substantial rearrangement to access the transition state structure.

\section{CONCLUSION}

Using a combination of high-resolution mass spectrometry and cryogenic ion vibrational spectroscopy techniques, we have isolated a non-covalently bound complex between an ortho-quinone and a $\left[\mathrm{Ru}^{\mathrm{II}}\left(\mathrm{en}^{*}\right)_{2}\right]^{2+}$ coordination compound that is known to undergo a double proton-coupled electron transfer reaction in solution. Vibrational characterization of both the isolated reactant ion and $\left[\mathrm{Ru}^{\mathrm{II}}\left(\mathrm{en}^{*}\right)_{2} \mathrm{TBOQ}^{2+}\right.$ reveals a double complexation motif in which two of the $\mathrm{C}=\mathrm{O}$ groups attach to two of the $\mathrm{NH}_{2}$ groups with strong hydrogen bonds. This is evidenced by the appearance of intense, red-shifted bands in the $\mathrm{NH}$ stretching region of the vibrational 
spectrum upon complexation and a strong $\mathrm{C}=\mathrm{O}$ fundamental in the lower energy region of the spectrum. Calculations indicate that the binary complex most likely corresponds to TBOQ attachment to two different classes of the $\mathrm{NH}_{2}$ groups: one axial and one equatorial with respect to the bipyridine ligand. Because the $\left[\mathrm{Ru}^{\mathrm{IV}}\left(\mathrm{en}^{*}-\mathrm{H}\right)_{2}\right]^{2+}$ product is formed with loss of $\mathrm{H}$ atoms from two equatorial $\mathrm{NH}_{2}$ groups, it appears that the transition state for the $2 \times$ PCET reaction requires substantial rearrangement from the geometry of the isolated complex in the gas phase. This is consistent with the observation that the reaction could not be promoted by collisional activation of the entrance channel complex. As such, this study establishes that emergent methods in cryogenic ion spectroscopy can indeed engage structural aspects of complex systems under study in contemporary synthesis, but also points out limitations in their ability to directly unravel complex reaction pathways.

\section{SUPPLEMENTARY MATERIAL}

See the supplementary material for supporting experimental and computational data, including sample preparation, mass spectrometric data (MS and MS/MS), vibrational predissociation spectra, experimental and calculated frequencies, Fermi resonance analysis, as well as rotatable structures (PDF).

\section{ACKNOWLEDGMENTS}

M.A.J. thanks the Air Force Office of Scientific Research (AFOSR) under Grant Nos. FA9550-17-1-0267 (DURIP) and FA9550-18-1-0213. F.S.M. thanks Professor David Russell and Michael Poltash (Texas A\&M) for useful discussions about their adaptation of a Thermo Fisher Scientific Exactive Plus in combination with an external ion source and Henk Terink from Thermo Fisher Scientific for technical support. E.H.P. thanks the National Institutes of Health for stipend support provided under Biophysical Training Grant No. 2T32GM008283-31. M.C. is a member of the Research Career (CONICET). M.C. thanks Consejo Nacional de Investigaciones Científicas y Técnicas (CONICET) and Agencia Nacional de Promoción Científica y Tecnológica (ANPCyT) from Argentina for financial support. J.M.M. thanks the U.S. National Institutes of Health under Grant No. 5R01GM050422.

\section{DATA AVAILABILITY}

The data that support the findings of this study are available from the corresponding author upon reasonable request.

\section{REFERENCES}

${ }^{1}$ A. B. Wolk, C. M. Leavitt, E. Garand, and M. A. Johnson, "Cryogenic ion chemistry and spectroscopy," Acc. Chem. Res. 47(1), 202-210 (2014).

${ }^{2}$ E. Garand, M. Z. Kamrath, P. A. Jordan, A. B. Wolk, C. M. Leavitt, A. B. McCoy, S. J. Miller, and M. A. Johnson, "Determination of noncovalent docking by infrared spectroscopy of cold gas-phase complexes," Science 335(6069), 694-698 (2012).

${ }^{3}$ A. Škríba, J. Schulz, and J. Roithová, "Monitoring of reaction intermediates in the gas phase: Ruthenium-catalyzed C-C coupling," Organometallics 33(23), 68686878 (2014).
${ }^{4}$ Y.-K. Li, S. Debnath, M. Schlangen, W. Schöllkopf, K. Asmis, and H. Schwarz, "Direct identification of acetaldehyde formation and characterization of the active site in the $\left[\mathrm{VPO}_{4}\right]^{+} / \mathrm{C}_{2} \mathrm{H}_{4}$ couple by gas-phase vibrational spectroscopy," Angew. Chem., Int. Ed. 131, 19044 (2019).

${ }^{5}$ J. A. Maner, D. T. Mauney, and M. A. Duncan, "Imaging charge transfer in a cation-pi system: Velocity-map imaging of Ag+(benzene) photodissociation," J. Phys. Chem. Lett. 6(22), 4493-4498 (2015).

${ }^{6}$ F. S. Menges, S. M. Craig, N. Tötsch, A. Bloomfield, S. Ghosh, H.-J. Krüger, and M. A. Johnson, "Capture of $\mathrm{CO}_{2}$ by a cationic nickel(I) complex in the gas phase and characterization of the bound, activated $\mathrm{CO}_{2}$ molecule by cryogenic ion vibrational predissociation spectroscopy," Angew. Chem., Int. Ed. 55(4), 1282-1285 (2016).

${ }^{7}$ A. B. Wolk, C. M. Leavitt, J. A. Fournier, M. Z. Kamrath, G. B. Wijeratne, T. A. Jackson, and M. A. Johnson, "Isolation and characterization of a peroxo manganese (III) dioxygen reaction intermediate using cryogenic ion vibrational predissociation spectroscopy," Int. J. Mass Spectrom. 354-355, 33-38 (2013).

${ }^{8}$ A. J. Ingram, A. B. Wolk, C. Flender, J. Zhang, C. J. Johnson, U. Hintermair, R. H. Crabtree, M. A. Johnson, and R. N. Zare, "Modes of activation of organometallic iridium complexes for catalytic water and C-H oxidation," Inorg. Chem. 53(1), 423-433 (2014).

${ }^{9} \mathrm{G}$. Yassaghi, L. Jašíková, and J. Roithová, “Gas-phase study of metal complexes with redox-active ligands," Int. J. Mass Spectrom. 407, 92-100 (2016).

${ }^{10}$ E. Andris, R. Navrátil, J. Jašík, M. Puri, M. Costas, L. Que, and J. Roithová, "Trapping iron(III)-Oxo species at the boundary of the "oxo wall": Insights into the nature of the Fe(III)-O bond," J. Am. Chem. Soc. 140(43), 14391-14400 (2018).

${ }^{11}$ F. S. Menges, E. H. Perez, S. C. Edington, C. H. Duong, N. Yang, and M. A. Johnson, "Integration of high-resolution mass spectrometry with cryogenic ion vibrational spectroscopy," J. Am. Soc. Mass Spectrom. 30(9), 1551-1557 (2019).

${ }^{12}$ V. Kopysov, A. Makarov, and O. V. Boyarkin, "Colors for molecular masses: Fusion of spectroscopy and mass spectrometry for identification of biomolecules," Anal. Chem. 87(9), 4607-4611 (2015).

${ }^{13}$ M. Cattaneo, S. A. Ryken, and J. M. Mayer, "Outer-sphere $2 \mathrm{e}^{-} / 2 \mathrm{H}^{+}$Transfer Reactions of Ruthenium(II)-Amine and Ruthenium(IV)-Amido Complexes," Angew. Chem., Int. Ed. 56(13), 3675-3678 (2017).

${ }^{14}$ M. Z. Kamrath, E. Garand, P. A. Jordan, C. M. Leavitt, A. B. Wolk, M. J. Van Stipdonk, S. J. Miller, and M. A. Johnson, "Vibrational characterization of simple peptides using cryogenic infrared photodissociation of $\mathrm{H}_{2}$-tagged, mass-selected ions," J. Am. Chem. Soc. 133(16), 6440-6448 (2011).

${ }^{15}$ S. Debnath, X. Song, M. R. Fagiani, M. L. Weichman, M. Gao, S. Maeda, T. Taketsugu, W. Schöllkopf, A. Lyalin, D. M. Neumark, and K. R. Asmis, " $\mathrm{CO}_{2}$ adsorption on $\mathrm{Ti}_{3} \mathrm{O}_{6}$ : A novel carbonate binding motif," J. Phys. Chem. C 123(13), 8439-8446 (2019).

${ }^{16}$ J. D. Mosley, J. W. Young, J. Agarwal, H. F. Schaefer, P. V. R. Schleyer, and M. A. Duncan, "Structural isomerization of the gas-phase 2-norbornyl cation revealed with infrared spectroscopy and computational chemistry," Angew. Chem. Int. Edit. 53(23), 5888-5891 (2014).

${ }^{17}$ C. Masellis, N. Khanal, M. Z. Kamrath, D. E. Clemmer, and T. R. Rizzo, "Cryogenic vibrational spectroscopy provides unique fingerprints for glycan identification," J. Am. Soc. Mass Spectrom. 28(10), 2217-2222 (2017).

${ }^{18}$ F. S. Menges, J. Lang, Y. Nosenko, C. Kerner, M. Gaffga, L. T. Ghoochany, W. R. Thiel, C. Riehn, and G. Niedner-Schatteburg, "Exploring the gas-phase activation and reactivity of a ruthenium transfer hydrogenation catalyst by experiment and theory in concert," J. Phys. Chem. A 121(23), 4422-4434 (2017).

${ }^{19}$ A. Fedorov, E. P. A. Couzijn, N. S. Nagornova, O. V. Boyarkin, T. R. Rizzo, and $\mathrm{P}$. Chen, "Structure and bonding of isoleptic coinage metal $(\mathrm{Cu}, \mathrm{Ag}, \mathrm{Au})$ dimethylaminonitrenes in the gas phase," J. Am. Chem. Soc. 132(39), 1378913798 (2010)

${ }^{20} \mathrm{H}$. Schwarz and K. R. Asmis, "Identification of active sites and structural characterization of reactive ionic intermediates by cryogenic ion trap vibrational spectroscopy," Chem.-Eur. J. 25(9), 2112-2126 (2019).

${ }^{21}$ C. M. Leavitt, A. B. Wolk, J. A. Fournier, M. Z. Kamrath, E. Garand, M. J. Van Stipdonk, and M. A. Johnson, "Isomer-specific IR-IR double resonance spectroscopy of D2-tagged protonated dipeptides prepared in a cryogenic ion trap," $J$. Phys. Chem. Lett. 3(9), 1099-1105 (2012). 
${ }^{22}$ Y. Zhao and D. G. Truhlar, "The M06 suite of density functionals for main group thermochemistry, thermochemical kinetics, noncovalent interactions, excited states, and transition elements: Two new functionals and systematic testing of four M06-class functionals and 12 other functionals," Theor. Chem. Acc. 120(1-3), 215-241 (2008).

${ }^{23}$ R. Krishnan, J. S. Binkley, R. Seeger, and J. A. Pople, "Self-consistent molecularorbital methods .20. Basis set for correlated wave-functions,” J. Chem. Phys. 72(1), 650-654 (1980).

${ }^{24}$ M. J. Frisch, G. W. Trucks, H. B. Schlegel, G. E. Scuseria, M. A. Robb, J. R. Cheeseman, G. Scalmani, V. Barone, B. Mennucci, G. A. Petersson, H. Nakatsuji, M. Caricato, X. Li, H. P. Hratchian, A. F. Izmaylov, J. Bloino, G. Zheng, J. L. Sonnenberg, M. Hada, M. Ehara, K. Toyota, R. Fukuda, J. Hasegawa, M. Ishida, T. Nakajima, Y. Honda, O. Kitao, H. Nakai, T. Vreven, J. A. Montgomery, J. E. Peralta, F. Ogliaro, M. Bearpark, J. J. Heyd, E. Brothers, K. N. Kudin, V. N. Staroverov, R. Kobayashi, J. Normand, K. Raghavachari, A. Rendell, J. C. Burant, S. S. Iyengar, J. Tomasi, M. Cossi, N. Rega, J. M. Millam, M. Klene, J. E. Knox, J. B. Cross, V. Bakken, C. Adamo, J. Jaramillo, R. Gomperts, R. E. Stratmann, O. Yazyev, A. J. Austin, R. Cammi, C. Pomelli, J. W. Ochterski, R. L. Martin, K. Morokuma, V. G. Zakrzewski, G. A. Voth, P. Salvador, J. J. Dannenberg, S. Dapprich, A. D. Daniels, Ö. Farkas, J. B. Foresman, J. V. Ortiz, J. Cioslowski, and D. J. Fox, GAUSSIAN 09, Revision D.01, Gaussian, Inc., Wallingford, CT, 2009.
${ }^{25}$ W.-H. Chiu, S.-M. Peng, and C.-M. Che, "Bis(amido)ruthenium(IV) complexes with 2,3-diamino-2,3-dimethylbutane. Crystal structure and reversible Ru(IV)amide/Ru(III)-amine and $\mathrm{Ru}(\mathrm{IV})$-amide/ $\mathrm{Ru}(\mathrm{II})$ amine redox couples in aqueous solution,” Inorg. Chem. 35(11), 3369-3374 (1996).

${ }^{26}$ T. Shimanouchi, Tables of Molecular Vibrational Frequencies Consolidated Volume I (National Bureau of Standards, 1972), pp. 1-160.

${ }^{27}$ M. Yilmaz, B. Aydin, O. Dogan, and O. Dereli, "Molecular structure and spectral investigations of 3,5-Di-tert-butyl-o-benzoquinone,” J. Mol. Struct. 1128, 345-354 (2017).

${ }^{28}$ D. Nematollahi and H. Shayani-Jam, "Electrochemical oxidation of 3,5di-tert-butylcatechol: Synthesis and characterization of the formed orthobenzoquinhydrone derivative," Electrochim. Acta 51(28), 6384-6388 (2006).

${ }^{29}$ C. Greve, E. T. J. Nibbering, and H. Fidder, "Hydrogen-bonding-induced enhancement of fermi resonances: A linear IR and nonlinear 2D-IR study of aniline-d(5)," J. Phys. Chem. B 117(49), 15843-15855 (2013).

${ }^{30}$ S. Mishra, J.-L. Kuo, and G. N. Patwari, "Hydrogen bond induced enhancement of fermi resonances in N-H...N hydrogen bonded complexes of anilines," Phys. Chem. Chem. Phys. 20(33), 21557-21566 (2018).

${ }^{31}$ R. P. Schmid, P. K. Chowdhury, J. Miyawaki, F. Ito, K. Sugawara, T. Nakanaga, H. Takeo, and $\mathrm{H}$. Jones, "Infrared spectroscopy of aniline-X $\left(\mathrm{X}=\mathrm{N}_{2}, \mathrm{CH}_{4}\right.$, $\mathrm{CHF}_{3}, \mathrm{CO}$ ) clusters and their corresponding cluster cations in the $\mathrm{NH}_{2}$-stretching vibration region," Chem. Phys. 218(3), 291-300 (1997). 